\title{
Anticancer and cardio-protective effects of liposomal doxorubicin in the treatment of breast cancer
}

This article was published in the following Dove Press journal:

Breast Cancer - Targets and Therapy

\section{Yesenia L Franco* \\ Tanaya R Vaidya* \\ Sihem Ait-Oudhia}

Center for Pharmacometrics and Systems Pharmacology, Department of Pharmaceutics, College of Pharmacy, University of Florida, Orlando, FL, USA

*These authors contributed equally to this work
Correspondence: Sihem Ait-Oudhia Center for Pharmacometrics and Systems Pharmacology, Department of Pharmaceutics, College of Pharmacy, University of Florida, 6550 Sanger Road, Office \# 469, Orlando, FL 32827, USA

$\mathrm{Tel}+\mathrm{I} 4073137037$

Fax +I 4073137030

Email sihem.bihorel@cop.ufl.edu

\begin{abstract}
Breast cancer (BC) is a highly prevalent disease, accounting for the second highest number of cancer-related mortalities worldwide. The anthracycline doxorubicin (DOX), isolated from Streptomyces peucetius var. caesius, is a potent chemotherapeutic drug that is successfully used to treat various forms of liquid and solid tumors and is currently approved to treat BC. DOX exerts its effects by intercalation into DNA and inhibition of topoisomerases I and II, causing damage to DNA and the formation of reactive oxygen species (ROS), resulting in the activation of caspases, which ultimately leads to apoptosis. Unfortunately, DOX also can cause cardiotoxicity, with patients only allowed a cumulative lifetime dose of $550 \mathrm{mg} / \mathrm{m}^{2}$. Efforts to decrease cardiotoxicity and to increase the blood circulation time of DOX led to the US Food and Drug Administration (FDA) approval of a PEGylated liposomal formulation (L-DOX), Doxil $^{\circledR}$ (known internationally as Caelyx ${ }^{\circledR}$ ). Both exhibit better cardiovascular safety profiles; however, they are not currently FDA approved for the treatment of metastatic BC. Here, we provide detailed insights into the mechanism of action of L-DOX and its most common side effects and highlight results of its use in clinical trials for the treatment of $\mathrm{BC}$ as single agent and in combination with other commonly used chemotherapeutics.
\end{abstract}

Keywords: doxil, caelyx, breast cancer, anti-tumor activity, cardiotoxicity

\section{Introduction}

Breast cancer $(\mathrm{BC})$ is the second most frequent cause of cancer-related deaths in women worldwide. It is a heterogeneous disease composed of multiple subtypes with distinct pathological features and clinical implications. Although men are affected, to a lesser degree, the most significant risk factors are gender (women) and older age. Other risk factors include obesity, estrogen exposure, alcohol consumption, and a family history. ${ }^{1}$ Over the past 2 decades, accumulating evidence, both clinical and experimental, has suggested that BCs with different histopathological and biological features exhibit distinct behaviors that lead to different treatment responses and, therefore, should be given different therapeutic strategies. ${ }^{2}$ On this basis, at diagnosis, BC patients are systematically tested for the presence of receptors, including estrogen receptor (ER), progesterone receptor (PR), and human epidermal growth factor receptor 2 (HER2), in order to explore tailored treatment options with molecularly targeted therapies. However, for patients who are triple negative (ER-, PR-, and HER2-), those who have innate or acquired resistance to targeted therapies, and patients whose disease has metastasized, traditional treatment options including surgery, radiotherapy, and chemotherapy are favored. 
Anthracycline-based chemotherapy with doxorubicin (DOX) is one of the most efficacious anticancer agents for both early- and late-stage BCs. ${ }^{3}$ DOX's mechanism of action (Figure 1) on cancer cells begins with its passive diffusion through the phospholipid bilayer membrane of malignant cells into the cytoplasm, where DOX is converted into a semiquinone and generates reactive oxygen species (ROS), causing free radical formation and oxidative stress. In the cytosol, DOX enters the mitochondria causing DNA damage and energetic stress. As a result, the mitochondria release the cytochrome $C$ protein, triggering the caspase cascade leading to cell death. From the cytosol, DOX translocates into the nucleus where it intercalates between double-stranded DNA helices and inhibits the enzymes topoisomerases I and II. The resulting damage to DNA leads to free radical generation, alkylation, and activation of the p53 pathway, hence inhibiting cell proliferation and inducing apoptosis. DOX can also hyperactivate the nuclear enzyme poly ADP ribose polymerase (PARP)-1, hence depleting the cell's energy, thereby resulting in autophagy. ${ }^{46}$

However, the potential therapeutic benefits of DOX are limited by the risk of cardiotoxicity, which has been evidently related to its lifetime cumulative dose. ${ }^{7-9}$ To overcome this hurdle, the liposomal DOX (L-DOX) formulation was developed in order to reduce DOX-associated cardiotoxicity while preserving its antitumor efficacy. ${ }^{10}$ The L-DOX formulation encapsulates DOX within a phospholipid bilayer that is coated with methoxypolyethylene glycol (Figure 2). The PEGylation protects the liposomes from recognition by the mononuclear phagocyte system (MPS) and allows a longer circulation time in the bloodstream while reducing the exposure of free DOX circulating in the plasma. Biodistribution studies have shown that L-DOX has the ability to deposit and/or penetrate tumors and release DOX. ${ }^{11}$ Although the mechanism of release of DOX from its liposomes is still unknown, a 10-fold higher exposure of L-DOX than DOX is observed in metastatic BC tissue as compared to healthy breast tissue, ${ }^{12}$ which is explained by the enhanced permeability retention effect. ${ }^{13}$ This indicates that a therapeutic approach with L-DOX is more targeted compared to DOX. A differential pharmacokinetic (PK) characteristic between the two formulations includes a decreased clearance (CL), a smaller volume of distribution, and a longer half-life for L-DOX compared to DOX as a result of the sequestration of liposomes, due to their increased size, in the sinusoidal lumen of the liver, which limits their flow from the fenestrations of the lumen into the hepatocytes as compared to free DOX. This is also believed to contribute to reduced hepatic extraction of L-DOX compared to DOX as a single agent. ${ }^{14}$ The latter being primarily metabolized in the liver to the major cytotoxic metabolites: doxorubicinol and cytotoxic aglycones. The PK properties of L-DOX as compared to DOX are summarized in Table 1.

The use of DOX as a stand-alone treatment has shown effectiveness in overall survival and response rate and time to disease progression. ${ }^{15}$ Its limitations are seen in its effect on healthy cells and the resulting adverse effects, with the most significant being cardiotoxicity. The comparison of safety profiles between DOX and L-DOX is summarized in Table 2 with the most common side effect for L-DOX being palmar-plantar erythrodysesthesia, a skin toxicity that can be managed with supportive care, unlike cardiotoxicity, which is significantly more prevalent for DOX. ${ }^{16}$ Although the mechanism of DOX-induced cardiotoxicity is not fully understood, its administration is dose limited. It was shown that the risk of DOX-induced cardiotoxicity increases with the increase in its cumulative lifetime dose to becoming irreversible (ie, cardiomyocytes death) when the latter reaches $450-550 \mathrm{mg} / \mathrm{m}^{2} .{ }^{17}$ The other major cardiotoxic effects of DOX are the occurrence of congestive heart failure (CHF) in $>20 \%$ of the treated patients. ${ }^{8}$ Additional but less detrimental adverse reactions include nausea, vomiting, gastrointestinal problems, neurological symptoms, and cutaneous injuries at the site of injection. ${ }^{4}$

While L-DOX has proven to be advantageous over DOX as a single agent, it is only indicated in the treatment of metastatic $\mathrm{BC}$ in combination with docetaxel, ${ }^{18}$ although it is frequently utilized as adjuvant therapy in metastatic BC. ${ }^{19}$ The comparative anticancer efficacies of these two drugs in addition to their use in combination with other anticancer agents in $\mathrm{BC}$ continue to be investigated. ${ }^{20}$ Table 3 summarizes the main findings of trials assessing regimens containing L-DOX. These trials evaluated the efficacy of several combinations in varied patient populations including both locally advanced and metastatic BCs as well as the elderly and in patients with previously treated BCs. Overall, L-DOX was effective and well tolerated in the majority of trials, making it a feasible treatment option when combined with other chemotherapeutics. In the present work, we sought to investigate L-DOX's efficacy on BC and its potential associated cardiac toxicity when combined with other chemotherapeutic or targeted therapy, with the goal of showcasing the beneficial effect of L-DOX over DOX on $\mathrm{BC}$ therapy and cardiac function. 


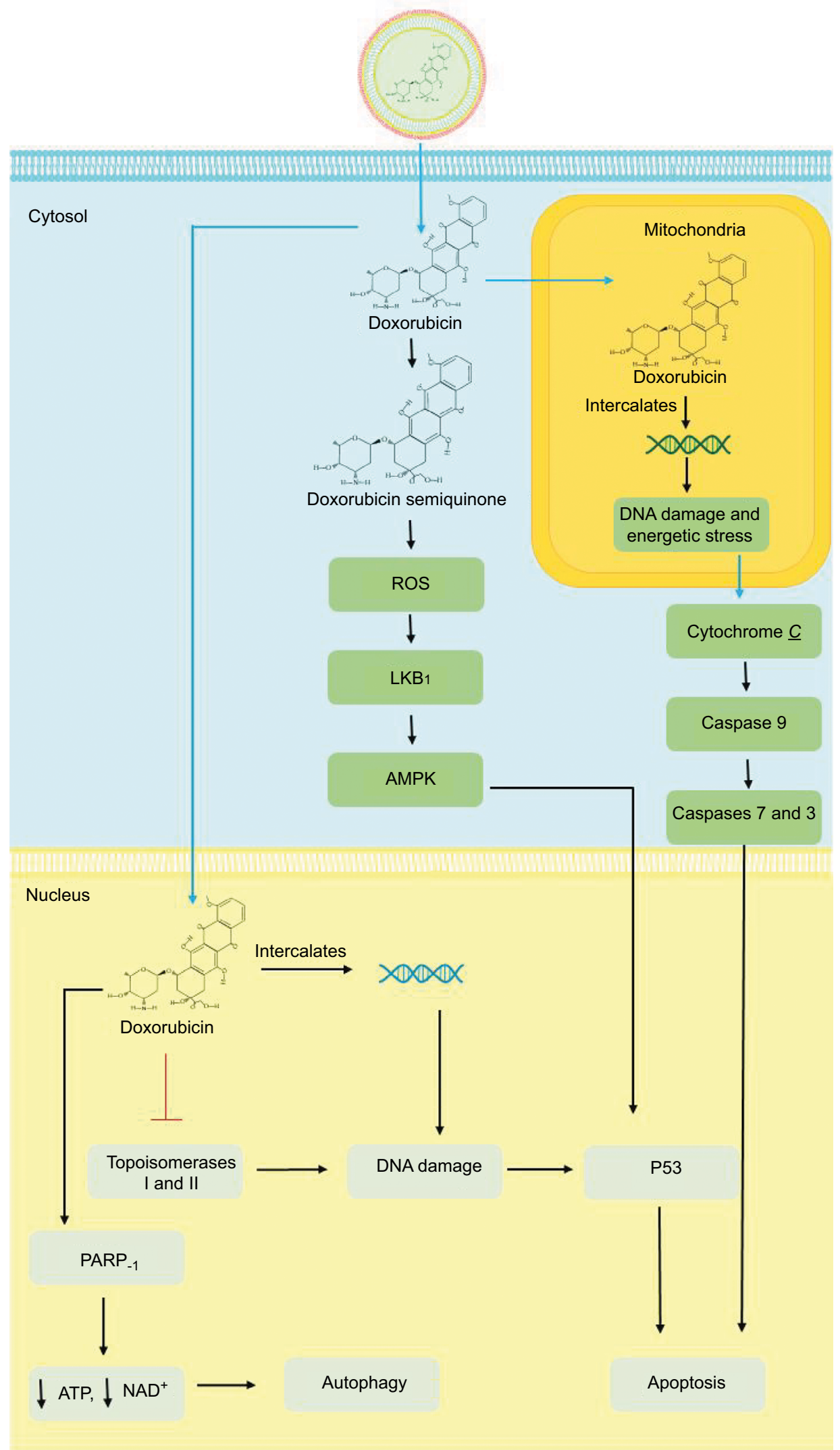

Figure I Mechanism of action of DOX and L-DOX.

Notes: Once L-DOX diffuses across the phospholipid bilayer of malignant cells, free DOX is released and it can be converted into a semiquinone or translocate into the nucleus or mitochondria. Conversion of DOX to a semiquinone causes the formation of ROS. DOX can also translocate to the nucleus where it intercalates between strands of DNA, inhibits topoisomerases I and II and activates PARP-I. In the mitochondria, DOX intercalates between strands of mitochondrial DNA and leads to the release of cytochrome $C$ and the activation of caspases. Ultimately, damage to nuclear and mitochondrial DNA as well as that caused by ROS leads to apoptosis. Abbreviations: DOX, doxorubicin; L-DOX, liposomal DOX; PARP, poly ADP ribose polymerase; ROS, reactive oxygen species. 


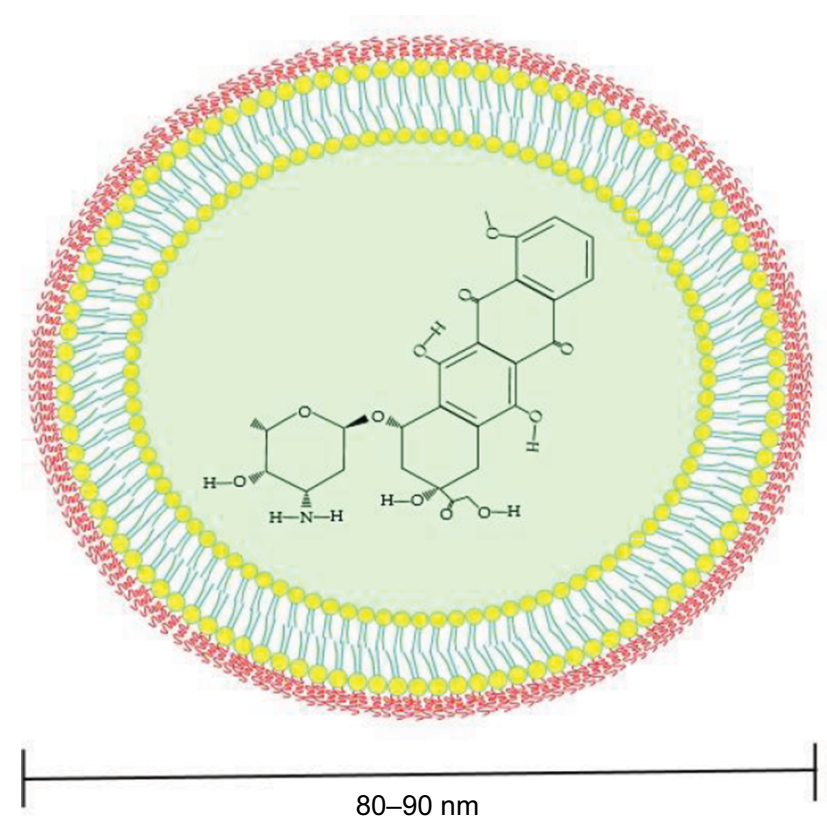

Figure 2 PEGylated liposomal DOX (Doxil $\left.{ }^{\circledR}\right)$.

Notes: DOX is surrounded by a phospholipid bilayer (liposome) that is coated with methoxypolyethylene glycol. Enclosing DOX in a liposome helps decrease systemic side effects while PEGylation protects the liposomes from recognition by the mononuclear phagocyte system and increases its circulation time.

Abbreviation: DOX, doxorubicin.

\section{Methods}

A literature search was conducted on PubMed, Google Scholar, and ClinicalTrials.gov using the following main keywords: liposomal DOX, Doxil ${ }^{\circledR}$ and BC, Caelyx ${ }^{\circledR}$ and BC, and Doxil ${ }^{\circledR}$ or Caelyx ${ }^{\circledR}$ and combinations in $\mathrm{BC}$, to obtain relevant publications evaluating the safety and efficacy of L-DOX in the treatment of breast tumors. Additionally, information regarding the PK and safety profiles of L-DOX and conventional DOX was acquired mainly from drug monographs. Publications assessed in this review included Phases II and III clinical trials of patients with BC, ranging from early to metastatic stages. No particular preference was given in regard to $\mathrm{BC}$ subtype, and the only criteria that needed to be met for combinations were the use of L-DOX in at least one arm with at least one additional agent.

\section{Results}

Tables 1 and 2 highlight the disparity in PK parameters and toxicity profiles between L-DOX and DOX. These can be attributed to differences in the formulation of the two agents, with the encapsulation of free DOX into a phospholipid bilayer

Table I Pharmacokinetic properties of DOX and L-DOX

\begin{tabular}{llll}
\hline Parameter (unit) & Definition & DOX, $\mathbf{m i n}-\mathbf{m a x}^{35}$ & L-DOX, average \pm SD $^{36}$ \\
\hline $\mathrm{CL}\left(\mathrm{mL} / \mathrm{min} / \mathrm{m}^{2}\right)$ & Plasma clearance & $324-809$ & $0.683 \pm 0.066$ \\
$T_{1 / 2}(\mathrm{~h})$ & Half-life & $20-48$ & $55 \pm 4.8$ \\
$V_{\mathrm{d}}\left(\mathrm{L} / \mathrm{m}^{2}\right)$ & Volume of distribution & $809-1,214$ & $2.72 \pm 0.12$ \\
$F_{\mathrm{b}}(\%)$ & Fraction bound to plasma proteins & $75^{\mathrm{a}}$ & Not determined \\
\hline
\end{tabular}

Note: a Data shown as average.

Abbreviations: CL, clearance; DOX, doxorubicin; L-DOX, liposomal DOX; SD, standard deviation.

Table 2 Comparison of use, efficacy, and safety profiles of DOX and L-DOX

\begin{tabular}{|c|c|c|}
\hline Criteria & $\operatorname{DOX}^{16,21,23}$ & L-DOX $\mathbf{X}^{16,22,24}$ \\
\hline \multirow[t]{3}{*}{ Indications } & $\begin{array}{l}\text { Label: leukemia, bladder cancer, breast cancer, gastric } \\
\text { cancer, sarcomas, small cell lung cancer among others }\end{array}$ & $\begin{array}{l}\text { Label: Kaposi’s sarcoma, multiple myeloma, } \\
\text { and ovarian cancer }\end{array}$ \\
\hline & Off label: biliary tract cancer, endometrial cancer, & Off label: use for breast cancer, cutaneous \\
\hline & Kaposi's sarcoma, malignant melanoma & T-cell lymphoma \\
\hline \multirow[t]{2}{*}{ Maximum dose limits } & Lifetime: up to $550 \mathrm{mg} / \mathrm{m}^{2} \mathrm{IV}$ & $50 \mathrm{mg}$ IV weekly \\
\hline & Up to $450 \mathrm{mg}$ IV if previous mediastinal radiation & $\begin{array}{l}\text { Safety and efficacy have not been established } \\
\text { in children and adolescents }\end{array}$ \\
\hline Black box warnings & Bone marrow suppression, cardiotoxicity, extravasation & Cardiotoxicity and infusion-related reactions \\
\hline \multirow[t]{5}{*}{ Adverse effects } & Cardiotoxicity & Palmar-plantar erythrodysesthesia \\
\hline & Nausea/vomiting & Nausea/vomiting \\
\hline & Alopecia & Alopecia \\
\hline & Leukopenia/neutropenia & Cardiotoxicity \\
\hline & Palmar-plantar erythrodysesthesia & Leukopenia/neutropenia \\
\hline
\end{tabular}

Abbreviations: DOX, doxorubicin; L-DOX, liposomal DOX; IV, intravenous. 
Table 3 Clinical trials with L-DOX in combination with other chemotherapeutics in breast cancer

\begin{tabular}{|c|c|c|c|}
\hline Drugs & Clinical trial & Main findings & References \\
\hline PLD and bevacizumab & Phase II & $46 \%$ of patients had grade three toxicities & 37 \\
\hline$-20 \mathrm{mg} / \mathrm{m}^{2} \mathrm{PLD}$ and $10 \mathrm{mg} / \mathrm{kg}$ & & ORR: $21 \%$ & \\
\hline bevacizumab given days I and I5 of & & Median PFS: 5.7 months & \\
\hline \multirow[t]{2}{*}{ 4-week cycle } & & Median OS: I5.9 months & \\
\hline & & Severe cardiotoxicity in one patient 4.7 months after treatment & \\
\hline PLD and bortezomib & Phase II & ORR: $8 \%$ & 38 \\
\hline - $1.3 \mathrm{mg} / \mathrm{m}^{2}$ bortezomib days I, 4,8 & & Median OS: 4.3 months & \\
\hline and $\mathrm{II}$ and $30 \mathrm{mg} / \mathrm{m}^{2}$ PLD day 4 of & & Median TTP: 1.3 months & \\
\hline 21 -day cycle & & $\begin{array}{l}\text { No cardiotoxicity reported despite prior anthracycline use in } 77 \% \\
\text { of patients }\end{array}$ & \\
\hline PLD and carboplatin (+ trastuzumab if & Phase II & PLD/carboplatin & 39 \\
\hline HER2+) & & IA: taxane naive & \\
\hline $30 \mathrm{mg} / \mathrm{m}^{2}$ PLD and carboplatin AUC $=$ & & ORR: $31 \%$ & \\
\hline $5 \mathrm{mg} * \mathrm{~min} / \mathrm{mL}$ day I of 21 -day cycle & & Median PFS: 8 months & \\
\hline If HER $2+$ also got $8 \mathrm{mg} / \mathrm{kg}$ loading dose & & IB: taxane pretreated & \\
\hline of trastuzumab and then $4 \mathrm{mg} / \mathrm{kg}$ days I & & ORR: $31 \%$ & \\
\hline \multirow[t]{8}{*}{ and 15 of 28 -day cycle } & & Median OS: 13 months & \\
\hline & & Median PFS: 5 months & \\
\hline & & PLD/carboplatin/trastuzumab & \\
\hline & & ORR: $56 \%$ & \\
\hline & & Median OS: 33 months & \\
\hline & & Median PFS: 10 months & \\
\hline & & No clinically significant cardiotoxicity. Declines in LVEF of at least & \\
\hline & & $15 \%$ in two patients in arm IA and one patient in trastuzumab arm & \\
\hline PLD, cisplatin, infusional 5-FU, and & Phase II & Clinical response rate: $94 \%$ & 31 \\
\hline trastuzumab & & 2-year DFS: $94 \%$ & \\
\hline $25 \mathrm{mg} / \mathrm{m}^{2}$ PLD, $60 \mathrm{mg} / \mathrm{m}^{2}$ cisplatin day & & No relevant cardiotoxicity - two patients had asymptomatic, & \\
\hline I and $200 \mathrm{mg} / \mathrm{m}^{2} 5-\mathrm{FU}$ as a continuous & & transient declines in LVEF of at least $20 \%$, but absolute LVEF was & \\
\hline infusion days $\mathrm{I}-2 \mathrm{I}$ of $2 \mathrm{I}$-day cycle & & maintained above $50 \%$ in both cases & \\
\hline \multicolumn{4}{|l|}{$8 \mathrm{mg} / \mathrm{kg}$ trastuzumab loading dose then } \\
\hline \multicolumn{4}{|l|}{$6 \mathrm{mg} / \mathrm{kg}$ on day 2 of cycle } \\
\hline PLD and cyclophosphamide & Phase II & Objective response: $51 \%$ & 40 \\
\hline Cohort I: $50 \mathrm{mg} / \mathrm{m}^{2}$ PLD day I and & & Clinical benefit rate (complete response + partial response + stable & \\
\hline $100 \mathrm{mg} / \mathrm{m}^{2}$ cyclophosphamide orally & & disease): $86 \%$ & \\
\hline days I-I4 (28-day cycle) & & Median DOR: 35.1 weeks & \\
\hline Cohort II: $30 \mathrm{mg} / \mathrm{m}^{2}$ PLD and $600 \mathrm{mg} /$ & & Median time-to-tumor progression: 34.4 weeks & \\
\hline $\mathrm{m}^{2}$ cyclophosphamide day I of 21 -day & & No clinical cardiotoxicity or significant declines in median LVEF & \\
\hline cycle & & following treatment & \\
\hline \multicolumn{4}{|l|}{ Cohort III: $35 \mathrm{mg} / \mathrm{m}^{2}$ and $600 \mathrm{mg}$} \\
\hline \multicolumn{4}{|l|}{ cyclophosphamide day I of 2I-day cycle } \\
\hline PLD and cyclophosphamide (in elderly & Phase II & Objective response rate: $28.6 \%$ & 41 \\
\hline patients between $65-75$ years old) & & Median PFS: 8.8 months & \\
\hline$-40 \mathrm{mg} / \mathrm{m}^{2} \mathrm{PLD}$ and $500 \mathrm{mg} / \mathrm{m}^{2}$ & & Median OS: 20.3 months & \\
\hline cyclophosphamide day I of 4-week & & Mucositis, myelosuppression in the elderly & \\
\hline cycle & & No reported cardiac toxicity or significant changes in LVEF & \\
\hline PLD, cyclophosphamide, and 5-FU & Phase II & ORR: $41.9 \%$ & 42 \\
\hline$-40 \mathrm{mg} / \mathrm{m}^{2} \mathrm{PLD}, 500 \mathrm{mg} / \mathrm{m}^{2}$ & & Median PFS: 8.2 months & \\
\hline cyclophosphamide, and $500 \mathrm{mg} / \mathrm{m}^{2} 5-\mathrm{FU}$ & & Median OS: 36.6 months & \\
\hline on day I of 21 -day cycle & & $\begin{array}{l}\text { No significant changes in LVEF, even after prior anthracycline } \\
\text { exposure }\end{array}$ & \\
\hline PLD, cyclophosphamide, and paclitaxel & Phase II & Overall pCR: $32 \%$ & 43 \\
\hline - $35 \mathrm{mg} / \mathrm{m}^{2}$ PLD, $600 \mathrm{mg} / \mathrm{m}^{2}$ & & Radiological ORR: $26 \%$ & \\
\hline cyclophosphamide every 4 weeks, and & & 5-year PFS: $58 \%$ & \\
\hline \multirow[t]{2}{*}{$80 \mathrm{mg} / \mathrm{m}^{2}$ paclitaxel weekly } & & 5 -year OS: $62 \%$ & \\
\hline & & No significant declines in LVEF or ECG changes; five cardiac events & \\
\hline
\end{tabular}


Table 3 (Continued)

\begin{tabular}{|c|c|c|c|}
\hline Drugs & Clinical trial & Main findings & References \\
\hline PLD, cyclophosphamide, and & \multirow[t]{6}{*}{ Phase II } & Objective response rate: $68.8 \%$ & \multirow[t]{6}{*}{27} \\
\hline trastuzumab & & Median OS: 34.2 months & \\
\hline $50 \mathrm{mg} / \mathrm{m}^{2} \mathrm{PLD}$ and $600 \mathrm{mg}$ & & Median TTP: 12 months & \\
\hline cyclophosphamide every 4 weeks & & No symptomatic CHF; declines in LVEF observed in eight of the & \\
\hline $4 \mathrm{mg} / \mathrm{kg}$ trastuzumab loading dose then & & 48 patients and reversed in seven patients (six of them had prior & \\
\hline $2 \mathrm{mg} / \mathrm{kg}$ weekly & & anthracycline exposure) & \\
\hline PLD, cyclophosphamide, docetaxel, and & \multirow[t]{10}{*}{ Phase II } & Objective response rate: $83 \%$ & \multirow[t]{10}{*}{44} \\
\hline trastuzumab (if $\mathrm{HER} 2+$ ) & & PCRT: I3\% & \\
\hline $35 \mathrm{mg} / \mathrm{m}^{2} \mathrm{PLD}$ and $600 \mathrm{mg}$ & & Normal LVEF maintained during the study & \\
\hline cyclophosphamide on day I of 2 I-day & & & \\
\hline cycle & & & \\
\hline $100 \mathrm{mg} / \mathrm{m}^{2}$ docetaxel day I of 21 -day & & & \\
\hline cycle & & & \\
\hline If HER2+ got $8 \mathrm{mg} / \mathrm{kg}$ loading dose of & & & \\
\hline trastuzumab then $6 \mathrm{mg} / \mathrm{kg}$ day I of & & & \\
\hline 2I-day cycles & & & \\
\hline PLD and docetaxel & \multirow[t]{7}{*}{ Phase II } & Overall clinical benefit: $47 \%$ & \multirow[t]{7}{*}{45} \\
\hline Group A: $35 \mathrm{mg} / \mathrm{m}^{2}$ PLD on day I and & & ORR: $49 \%$ & \\
\hline $40 \mathrm{mg} / \mathrm{m}^{2}$ docetaxel days I and 15 of & & High rates of toxicity in both groups & \\
\hline 28-day cycle & & No significant cardiotoxicity & \\
\hline Group B: $30 \mathrm{mg} / \mathrm{m}^{2}$ PLD day I and & & & \\
\hline $75 \mathrm{mg} / \mathrm{m}^{2}$ docetaxel day 2 (3-week & & & \\
\hline cycle) & & & \\
\hline PLD and docetaxel (trastuzumab if & \multirow[t]{11}{*}{ Phase II } & PLD/docetaxel & \multirow[t]{11}{*}{46} \\
\hline $\mathrm{HER} 2+)$ & & ORR: $47.4 \%$ & \\
\hline Group A: $30 \mathrm{mg} / \mathrm{m}^{2}$ PLD and $60 \mathrm{mg} / \mathrm{m}^{2}$ & & Median PFS: I I months & \\
\hline docetaxel every 3 weeks & & Median OS: 24.6 months & \\
\hline Group B: 30 mg/m² PLD, 60 mg/m² & & PLD/docetaxel/trastuzumab & \\
\hline docetaxel every 3 weeks, and $4 \mathrm{mg} / \mathrm{kg}$ & & ORR: $45.7 \%$ & \\
\hline trastuzumab loading dose then $2 \mathrm{mg} /$ & & Median PFS: 10.6 months & \\
\hline \multirow[t]{4}{*}{ kg weekly } & & Median OS: 31.8 months & \\
\hline & & Higher rates of hand foot syndrome & \\
\hline & & Incidence of $\mathrm{CHF}<3 \%$ and the addition of trastuzumab did not & \\
\hline & & increase CHF risk & \\
\hline PLD and docetaxel vs docetaxel (in & \multirow[t]{10}{*}{ Phase III } & PLD/docetaxel & \multirow[t]{10}{*}{47} \\
\hline patients who experienced a relapse & & Objective response rate: $35 \%$ & \\
\hline following adjuvant anthracycline use) & & Median TTP: 9.8 months & \\
\hline$-30 \mathrm{mg} / \mathrm{m}^{2} \mathrm{PLD}$ and $60 \mathrm{mg} / \mathrm{m}^{2}$ & & Median OS: 20.5 months & \\
\hline docetaxel (2l-day cycle) vs $75 \mathrm{mg} / \mathrm{m}^{2}$ & & Docetaxel & \\
\hline \multirow[t]{5}{*}{ docetaxel (2I-day cycle) } & & Objective response rate: $26 \%$ & \\
\hline & & Median TTP: 7 months & \\
\hline & & Median OS: 20.6 months & \\
\hline & & No significant increase in CHF incidence or LVEF decline with the & \\
\hline & & addition of PLD & \\
\hline PLD and GEM & \multirow[t]{5}{*}{ Phase II } & ORR: $47.8 \%$ & \multirow[t]{5}{*}{48} \\
\hline - $25 \mathrm{mg} / \mathrm{m}^{2}$ PLD day I and $800 \mathrm{mg} / \mathrm{m}^{2}$ & & Median TTP: 7 months & \\
\hline \multirow[t]{3}{*}{ GEM on days I and 8 of 2 I-day cycle } & & Median duration of clinical benefit: 8 months & \\
\hline & & Mild cardiac toxicity in $4 \%$ patients; it was recovered after the end & \\
\hline & & of the study & \\
\hline PLD and GEM & \multirow[t]{6}{*}{ Phase II } & ORR: $52 \%$ & \multirow[t]{6}{*}{49} \\
\hline - $24 \mathrm{mg} / \mathrm{m}^{2}$ PLD day I and $800 \mathrm{mg} / \mathrm{m}^{2}$ & & Median OS: 16.1 months & \\
\hline \multirow[t]{4}{*}{ GEM days I and 8 (2I-day cycle) } & & Median TTP: 4.5 months & \\
\hline & & Clinical benefit: $78 \%$ & \\
\hline & & Minimal cardiotoxicity, with a transient decline in LVEF in one & \\
\hline & & patient, who recovered after the end of the study & \\
\hline
\end{tabular}


Table 3 (Continued)

\begin{tabular}{|c|c|c|c|}
\hline Drugs & Clinical trial & Main findings & References \\
\hline PLD and GEM & Phase II & ORR: $39.1 \%$ & 50 \\
\hline - $25 \mathrm{mg} / \mathrm{m}^{2}$ PLD and $800 \mathrm{mg} / \mathrm{m}^{2}$ GEM & & Median TTP: II months & \\
\hline \multirow[t]{2}{*}{ days I and 8 of 2 I-day cycle } & & Overall clinical benefit: $85.9 \%$ & \\
\hline & & $\begin{array}{l}\text { Only one case of cardiac toxicity was observed, despite } 41 \% \text { of } \\
\text { patients having undergone prior anthracycline therapy }\end{array}$ & \\
\hline PLD, GEM and docetaxel & Phase II & ORR: $74 \%$ & 51 \\
\hline - I,000 mg/m² GEM on day I followed & & No cardiotoxicity was observed as per protocol-defined criteria & \\
\hline by $800 \mathrm{mg} / \mathrm{m}^{2} \mathrm{GEM}, 75 \mathrm{mg} / \mathrm{m}^{2}$ & & and all patients maintained LVEF $>50 \%$ & \\
\hline \multicolumn{4}{|l|}{ docetaxel, and $30 \mathrm{mg} / \mathrm{m}^{2}$ PLD on day 8} \\
\hline \multicolumn{4}{|l|}{ (3-week cycles) } \\
\hline PLD and lapatinib & Phase II & ORR: $54 \%$ & 52 \\
\hline - I,250 mg lapatinib daily and $40 \mathrm{mg} / \mathrm{m}^{2}$ & & Median PFS: 5.8 months & \\
\hline \multirow[t]{2}{*}{ PLD every 4 weeks } & & Median OS: 23.3 months & \\
\hline & & No cardiac events were observed & \\
\hline PLD (low dose) and paclitaxel & Phase II & Objective response rate: $74 \%$ & 53 \\
\hline$-15 \mathrm{mg} / \mathrm{m}^{2}$ PLD every other week and & & $9 \%$ pathological complete response on breast and axilla & \\
\hline \multirow[t]{2}{*}{$80 \mathrm{mg} / \mathrm{m}^{2}$ paclitaxel weekly } & & $55 \%$ had breast conserving surgery & \\
\hline & & No impairment of cardiac function was observed & \\
\hline PLD and paclitaxel & Phase II & Objective response rate: $80 \%$ & 54 \\
\hline$-30 \mathrm{mg} / \mathrm{m}^{2} \mathrm{PLD}$ and $175 \mathrm{mg} / \mathrm{m}^{2}$ & & Median duration of objective response: 31 weeks & \\
\hline \multirow[t]{4}{*}{ paclitaxel (3-week cycles) } & & Median time to treatment failure: 45 weeks & \\
\hline & & Decline in LVEF was observed in eight of the 26 patients; however, & \\
\hline & & no clinical signs or symptoms of cardiac toxicity/failure were & \\
\hline & & observed & \\
\hline PLD and trastuzumab & Phase II & Clinical benefit: $50 \%$ & 30 \\
\hline - $40 \mathrm{mg} / \mathrm{m}^{2}$ PLD every 4 weeks and & & Median PFS: 9.67 months & \\
\hline $4 \mathrm{mg} / \mathrm{kg}$ trastuzumab loading dose then & & Median OS: 16.23 months & \\
\hline \multirow[t]{2}{*}{$2 \mathrm{mg} / \mathrm{kg}$ weekly } & & Three of the 16 patients developed decline in LVEF; a clinically & \\
\hline & & relevant and symptomatic decrease occurred in only one patient & \\
\hline PLD and trastuzumab & Phase II & ORR: $52 \%$ & 28 \\
\hline - $50 \mathrm{mg} / \mathrm{m}^{2}$ PLD every 4 weeks and & & Median DOR: II.I months & \\
\hline $4 \mathrm{mg} / \mathrm{kg}$ trastuzumab loading dose then & & Median PFS: 12 months & \\
\hline \multirow[t]{2}{*}{$2 \mathrm{mg} / \mathrm{kg}$ weekly } & & $10 \%$ of the patients developed protocol-defined cardiotoxicity, & \\
\hline & & albeit without any symptoms of $\mathrm{CHF}$ & \\
\hline PLD and trastuzumab & Phase II & ORR: $22 \%$ & 55 \\
\hline - $30 \mathrm{mg} / \mathrm{m}^{2} \mathrm{PLD}$ and $8 \mathrm{mg} / \mathrm{kg}$ & & Median PFS: 6.5 months & \\
\hline trastuzumab loading dose then $6 \mathrm{mg} / \mathrm{kg}$ & & Median OS: 18.7 months & \\
\hline \multirow[t]{3}{*}{ (3-week cycles) } & & Severe cardiotoxicity as per protocol-defined criteria was not & \\
\hline & & recorded. Median LVEF was maintained at $62 \%$ throughout the & \\
\hline & & study & \\
\hline PLD and VNB & Phase II & Objective response rate: $36 \%$ & 56 \\
\hline - $30 \mathrm{mg} / \mathrm{m}^{2}$ PLD day $\mathrm{I}$ and $20 \mathrm{mg} / \mathrm{m}^{2}$ & & Median PFS: 6.7 months & \\
\hline \multirow[t]{2}{*}{ VNB on days I and 8 (3-week cycles) } & & Median OS: 13.2 months & \\
\hline & & No cardiotoxicity was observed & \\
\hline PLD and VNB & Phase II & ORR: $39 \%$ & 29 \\
\hline - $40 \mathrm{mg} / \mathrm{m}^{2}$ PLD day 2 and $25 \mathrm{mg} / \mathrm{m}^{2}$ & & Median TTP: 6.5 months & \\
\hline \multirow[t]{4}{*}{ VNB on days I and I5 (4-week cycles) } & & Median OS: 14.5 months & \\
\hline & & Four of the 36 patients developed a decline in LVEF (>15\%); all four & \\
\hline & & had received prior anthracycline treatment. There were no clinical & \\
\hline & & symptoms of cardiac failure & \\
\hline PLD and VNB & Phase II & ORR: $35 \%$ & 57 \\
\hline - $35 \mathrm{mg} / \mathrm{m}^{2}$ PLD day $\mathrm{I}$ and $30 \mathrm{mg} / \mathrm{m}^{2}$ & & Median TTP: 7 months & \\
\hline \multirow[t]{4}{*}{ VNB day I (4-week cycles) } & & Median OS: 13 months & \\
\hline & & Three of the 33 patients had a significant decline in LVEF $(<50 \%)$ & \\
\hline & & none had clinical cardiac symptoms and cardiac function recovered & \\
\hline & & for two patients after cessation of treatment & \\
\hline
\end{tabular}


Table 3 (Continued)

\begin{tabular}{lll}
\hline Drugs & Clinical trial & Main findings \\
\hline EPI/VNB vs PLD/VNB & Phase II & EPI/VNB: \\
$-90 \mathrm{mg} / \mathrm{m}^{2}$ EPI day I and $25 \mathrm{mg} / \mathrm{m}^{2}$ & & ORR: $42.6 \%$ \\
VNB days I and 5 (2I-day cycle) & & Median PFS: 10.7 months \\
$40 \mathrm{mg} / \mathrm{m}^{2}$ PLD day I and $30 \mathrm{mg} / \mathrm{m}^{2}$ & Median OS: 34.6 months \\
VNB days I and I5 (4-week cycles) & PLD/VNB: \\
& ORR: $52 \%$ \\
& Median PFS: 8.8 months \\
& Median OS: 24.8 months \\
& No cases of CHF, two transient LVEF decreases in arm EPI/VNB \\
& that resolved in 2 months
\end{tabular}

Abbreviations: 5-FU, 5-fluorouracil; AUC, area under the concentration curve; CHF, congestive heart failure; DFS, disease-free survival; DOR, duration of response; ECG, electrocardiogram; EPI, epirubicin; GEM, gemcitabine; HER2, human epidermal growth factor receptor 2; L-DOX, liposomal doxorubicin; LVEF, left ventricular ejection fraction; ORR, overall response rate; OS, overall survival; PCR, pathological complete response; pCRT, total pathological complete response; PFS, progression-free survival; PLD, PEGylated L-DOX; TTP, time to progression; VNB, vinorelbine.

and exterior PEGylation of the liposomes providing improvements in terms of increasing the drug's half-life $\left(T_{1 / 2}\right)$, decreasing both the volume of distribution $\left(V_{\mathrm{d}}\right)$ and plasma CL, and reducing the severity of toxicity associated with the use of anthracyclines. L-DOX's decreased CL ( 0.7 vs $324-809 \mathrm{~mL} /$ $\mathrm{min} / \mathrm{m}^{2}$ for DOX) and increased $T_{1 / 2}(55 \pm 4.8 \mathrm{vs} 20-48 \mathrm{~h}$ for DOX) may be attributed to decreased metabolism by the liver and MPS. L-DOX liposomes are $\sim 80-90 \mathrm{~nm}$ in diameter, although some references state that the size of the molecule is $\geq 100 \mathrm{~nm}$, a characteristic that impedes their passage across hepatic sinusoidal epithelial fenestrations and decreases their metabolism by hepatocytes. In addition, PEGylation of liposomes decreases their opsonization by immunoglobulin/ complement proteins and their uptake by phagocytic cells of the MPS (eg, Kupffer cells and splenic macrophages), thus prolonging the agent's plasma circulation time.

Another advantage of L-DOX is its extremely small volume of distribution in comparison to that of DOX $\left(2.72 \pm 0.12\right.$ vs $\left.809-1,214 \mathrm{~L} / \mathrm{m}^{2}\right)$. While DOX's large $V_{\mathrm{d}}$ indicates that it can effectively distribute into all compartments of the body, its lack of selectivity for tumors means that it can cause a wide range of toxicities. In contrast, the small volume of distribution of L-DOX indicates that the drug is mostly confined into the vascular space, with little free DOX available, as the drug is contained within the liposomes and does not distribute freely to healthy tissues. The small size of L-DOX allows it to extravasate more selectively across fenestrations in the epithelium of blood vessels supplying tumors, where it releases DOX, meaning that generally the use of L-DOX is associated with milder side effects. ${ }^{5,14}$ The classic adverse effect associated with DOX use is cardiotoxicity that can range in severity from an acute form that develops shortly after exposure to DOX to a more severe late form where patients may experience decreases in left ventricular ejection fraction (LVEF) and a subsequent diagnosis of DOX induced CHF. Furthermore, the use of DOX is limited by a cumulative lifetime dose limit of up to 550 or $450 \mathrm{mg} / \mathrm{m}^{2}$ if a patient received previous mediastinal radiation. In contrast, the more common toxicities from L-DOX use include palmar-plantar erythrodysesthesia, nausea, and alopecia. ${ }^{16,21-25}$

Since DOX is considered one of the most effective chemotherapy drugs available, it is often added to regimens for localized or metastatic BC as first- or second-line therapy, as a part of a neoadjuvant therapy prior to surgery or as a salvage therapy. Although it is an effective agent, the risks of cardiotoxicity, particularly when combined with other medications associated with the development of CHF, such as trastuzumab and cyclophosphamide, can limit its use. ${ }^{26}$ In the case of L-DOX, the decreased rates of cardiotoxicity due to the formulation/PK differences described in the preceding paragraph allows its inclusion in regimens where free DOX would have a high risk of cardiotoxicity. Table 3 summarizes several trials where L-DOX has been combined with other chemotherapeutics or targeted therapies. Of note, a study combining L-DOX, trastuzumab, and cyclophosphamide was one of the most effective, with an overall survival of 34.2 months and the progression-free survival (PFS) of 12 months. ${ }^{27}$ In terms of toxicity, eight of the 48 included patients experienced asymptomatic decreases in LVEF and all but one recovered; of the affected patients, six patients had prior exposure to anthracyclines. As for the other trials included in Table 3, a majority did not find any significant changes to LVEF or high incidences of clinically relevant 
cardiotoxicity; however, in several instances where mild-tomoderate cardiotoxicity was reported, it was often in patients who either had prior anthracycline exposure or were concurrently being treated with trastuzumab. ${ }^{27-31}$

\section{Discussion}

The decreased risk for the cardiotoxicity of L-DOX combined with its comparable efficacy to DOX in the treatment of BC has made it a suitable alternative therapy in treatment regimens that traditionally utilized conventional DOX. ${ }^{16}$ In the in vivo setting, the prolonged systemic circulation of L-DOX due to its relatively long half-life, ${ }^{32}$ along with its selective delivery to the tumor site due to its extravasation through leaky tumor vasculature, ${ }^{33}$ results in a higher tumor accumulation as compared to normal tissues. In addition, circulating free-drug concentrations in plasma are reduced due to the highly stable L-DOX formulation, leading to lower cardiac tissue exposure of free-DOX, as compared to tumor tissue. Thus, the use of L-DOX would not only be able to alleviate cardiotoxicity but also to retain significant cytotoxic activity against target tumor cells, due to differences in exposure as well as relative potency of DOX in both tissue types. This is in agreement with results from a Phase III study, ${ }^{16}$ where L-DOX was shown to be as efficacious as DOX, with significantly reduced cardiotoxicity and other adverse events, in patients with metastatic BC.

Table 3 summarizes all clinical trials for combinatorial effects of L-DOX with other chemotherapeutics and targeted agents. It is noted that practically all trials are Phase II, and the cardiotoxic events observed were either very low or not existent. In most cases where patients experienced mild-to-moderate cardiotoxicity, they were reported to have received prior anthracycline therapy or were on regimens that included trastuzumab, which is known to augment cardiotoxicity caused due to DOX. ${ }^{34}$ Nevertheless, the cardiotoxicity observed in the case of L-DOX was significantly lower than that observed with DOX, thus establishing the cardiac safety of this formulation and supporting its clinical use.

In this work, we sought to discuss the therapeutic use of L-DOX in BC. A review of available Phase II and III trials in $\mathrm{BC}$ patients has demonstrated that the use of L-DOX generally causes very little cardiotoxicity, while retaining efficacy when used in combination with other chemotherapeutics. Together, this information suggests that L-DOX should continue to be evaluated in further Phase II and III trials in BC, as it remains an effective agent when combined with other chemotherapeutics and is a reasonable agent to substitute in the place of conventional DOX, particularly in patients who are at higher risk for cardiotoxicity.

\section{Disclosure}

The authors report no conflicts of interest in this work.

\section{References}

1. BreastCancer.Org [webpage on the Internet]. U.S Breast Cancer Statisctics. 2016. Available from: http://www.breastcancer.org/symptoms/ understand_bc/statistics. Accessed December 11, 2016.

2. Nakada H, Nakagomi H, Hirotsu Y, et al. A study of tumor heterogeneity in a case with breast cancer. Breast Cancer. 2017;24(3):483-489.

3. Early Breast Cancer Trialists' Collaborative Group (EBCTCG). Effects of chemotherapy and hormonal therapy for early breast cancer on recurrence and 15-year survival: an overview of the randomised trials. Lancet. 2005;365(9472):1687-1717.

4. Tacar O, Sriamornsak P, Dass CR. Doxorubicin: an update on anticancer molecular action, toxicity and novel drug delivery systems. J Pharm Pharmacol. 2013;65(2):157-170.

5. Gabizon AA, Patil Y, La-Beck NM. New insights and evolving role of pegylated liposomal doxorubicin in cancer therapy. Drug Resist Updat. 2016;29:90-106.

6. Ott M, Robertson JD, Gogvadze V, Zhivotovsky B, Orrenius S. Cytochrome c release from mitochondria proceeds by a two-step process. Proc Natl Acad Sci U S A. 2002;99(3):1259-1263.

7. Shan K, Lincoff AM, Young JB. Anthracycline-induced cardiotoxicity. Ann Intern Med. 1996;125(1):47-58.

8. Swain SM, Whaley FS, Ewer MS. Congestive heart failure in patients treated with doxorubicin: a retrospective analysis of three trials. Cancer. 2003;97(11):2869-2879.

9. Bria E, Cuppone F, Fornier M, et al. Cardiotoxicity and incidence of brain metastases after adjuvant trastuzumab for early breast cancer: the dark side of the moon? A meta-analysis of the randomized trials. Breast Cancer Res Treat. 2008;109(2):231-239.

10. Lao J, Madani J, Puértolas T, et al. Liposomal doxorubicin in the treatment of breast cancer patients: a review. J Drug Deliv. 2013;2013:456409-456412.

11. Janssen. Caelyx Product Monograph. 2011. Available from: https:// www.janssen.com/canada/sites/www_janssen_com_canada/files/ prod_files/live/caelyx_cpm.pdf. Accessed August 20, 2018.

12. Minchinton AI, Tannock IF. Drug penetration in solid tumours. Nat Rev Cancer. 2006;6(8):583-592.

13. Nichols JW, Bae YH. EPR: evidence and fallacy. J Control Release. 2014;190:451-464.

14. Hilmer SN, Cogger VC, Muller M, Le Couteur DG. The hepatic pharmacokinetics of doxorubicin and liposomal doxorubicin. Drug Metab Dispos. 2004;32(8):794-799.

15. Rivera E. Liposomal anthracyclines in metastatic breast cancer: clinical update. Oncologist. 2003;8(suppl 2):3-9.

16. O'Brien ME, Wigler N, Inbar M, et al; CAELYX Breast Cancer Study Group. Reduced cardiotoxicity and comparable efficacy in a phase III trial of pegylated liposomal doxorubicin $\mathrm{HCl}$ (CAELYX/Doxil) versus conventional doxorubicin for first-line treatment of metastatic breast cancer. Ann Oncol. 2004;15(3):440-449.

17. Doxil - Dosing for progressed or recurrent ovarian cancer [webpage on the Internet]. Janssen Products, LP; 2018. Available from: https:// www.doxil.com/hcp/progressed-or-recurrent-ovarian-cancer/. Accessed August 20, 2018.

18. FDA Approves Supplemental New Drug Application for DOXIL [webpage on the Internet]. Manchester: News Medical Life Sciences; 2009. Available from: http://www.news-medical.net/news/20090910/ FDA-approves-Supplemental-New-Drug-Application-for-DOXIL.aspx. Accessed August 20, 2018.

19. Espelin CW, Leonard SC, Geretti E, Wickham TJ, Hendriks BS. Dual HER2 Targeting with trastuzumab and liposomal-encapsulated doxorubicin (MM-302) demonstrates synergistic antitumor activity in breast and gastric cancer. Cancer Res. 2016;76(6):1517-1527.

20. Rafiyath SM, Rasul M, Lee B, Wei G, Lamba G, Liu D. Comparison of safety and toxicity of liposomal doxorubicin vs. conventional anthracyclines: a meta-analysis. Exp Hematol Oncol. 2012;1(1):10. 
21. Friberg LE, Karlsson MO. Mechanistic models for myelosuppression. Invest New Drugs. 2003;21(2):183-194.

22. Friberg LE, Hassan SB, Lindhagen E, Larsson R, Karlsson MO. Pharmacokinetic-pharmacodynamic modelling of the schedule-dependent effect of the anti-cancer agent CHS 828 in a rat hollow fibre model. Eur J Pharm Sci. 2005;25(1):163-173.

23. Minami H, Sasaki Y, Saijo N, et al. Indirect-response model for the time course of leukopenia with anticancer drugs. Clin Pharmacol Ther. 1998;64(5):511-521.

24. Friberg LE, Brindley CJ, Karlsson MO, Devlin AJ. Models of schedule dependent haematological toxicity of 2'-deoxy-2'-methylidenecytidine (DMDC). Eur J Clin Pharmacol. 2000;56(8):567-574.

25. Outomuro D, Grana DR, Azzato F, Milei J. Adriamycin-induced myocardial toxicity: new solutions for an old problem? Int J Cardiol. 2007;117(1):6-15.

26. Bovelli D, Plataniotis G, Roila F; ESMO Guidelines Working Group. Cardiotoxicity of chemotherapeutic agents and radiotherapy-related heart disease: ESMO clinical practice guidelines. Ann Oncol. 2010;21(suppl 5):v277-v282.

27. Martín M, Sánchez-Rovira P, Muñoz M, et al; GEICAM. Pegylated liposomal doxorubicin in combination with cyclophosphamide and trastuzumab in HER2-positive metastatic breast cancer patients: efficacy and cardiac safety from the GEICAM/2004-05 study. Ann Oncol. 2011;22(12):2591-2596.

28. Chia S, Clemons M, Martin LA, et al. Pegylated liposomal doxorubicin and trastuzumab in HER-2 overexpressing metastatic breast cancer: a multicenter phase II trial. J Clin Oncol. 2006;24(18):2773-2778.

29. Ardavanis A, Mavroudis D, Kalbakis K, et al. Pegylated liposomal doxorubicin in combination with vinorelbine as salvage treatment in pretreated patients with advanced breast cancer: a multicentre phase II study. Cancer Chemother Pharmacol. 2006;58(6):742-748.

30. Stickeler E, Klar M, Watermann D, et al. Pegylated liposomal doxorubicin and trastuzumab as 1st and 2nd line therapy in her2/neu positive metastatic breast cancer: a multicenter phase II trial. Breast Cancer Res Treat. 2009;117(3):591-598.

31. Torrisi R, Cardillo A, Cancello G, et al. Phase II trial of combination of pegylated liposomal doxorubicin, cisplatin, and infusional 5-fluorouracil (CCF) plus trastuzumab as preoperative treatment for locally advanced and inflammatory breast cancer. Clin Breast Cancer. 2010;10(6):483-488.

32. Gabizon A, Catane R, Uziely B, et al. Prolonged circulation time and enhanced accumulation in malignant exudates of doxorubicin encapsulated in polyethylene-glycol coated liposomes. Cancer Res. 1994;54(4):987-992.

33. Soloman R, Gabizon AA. Clinical pharmacology of liposomal anthracyclines: focus on pegylated liposomal doxorubicin. Clin Lymphoma Myeloma. 2008;8(1):21-32.

34. Romond EH, Jeong JH, Rastogi P, et al. Seven-year follow-up assessment of cardiac function in NSABP B-31, a randomized trial comparing doxorubicin and cyclophosphamide followed by paclitaxel (ACP) with ACP plus trastuzumab as adjuvant therapy for patients with nodepositive, human epidermal growth factor receptor 2-positive breast cancer. J Clin Oncol. 2012;30(31):3792-3799.

35. Doxorubicin full prescribing information [webpage on the internet]. DAILYMED. Available from: https://dailymed.nlm.nih.gov/dailymed/dru gInfo.cfm?setid=1fd148fb-0fbc-4b6f-b790-23546fb46a71\#section-11.2. Accessed August 20, 2018.

36. Doxil full prescribing information [webpage on the internet]. DAILYMED. Available from: https://dailymed.nlm.nih.gov/dailymed/drugInfo. cfm?setid=21d9c619-7e94-49e2-ac41-31e9ea96554a\#section-11.2. Accessed August 20, 2018.

37. Rochlitz C, Ruhstaller T, Lerch S, et al; Swiss Group for Clinical Cancer Research (SAKK). Combination of bevacizumab and 2-weekly pegylated liposomal doxorubicin as first-line therapy for locally recurrent or metastatic breast cancer. A multicenter, single-arm phase II trial (SAKK 24/06). Ann Oncol. 2011;22(1):80-85.

38. Irvin WJ, Orlowski RZ, Chiu WK, et al. Phase II study of bortezomib and pegylated liposomal doxorubicin in the treatment of metastatic breast cancer. Clin Breast Cancer. 2010;10(6):465-470.
39. Collea RP, Kruter FW, Cantrell JE, et al. Pegylated liposomal doxorubicin plus carboplatin in patients with metastatic breast cancer: a phase II study. Ann Oncol. 2012;23(10):2599-2605.

40. Overmoyer B, Silverman P, Holder LW, Tripathy D, Henderson IC. Pegylated liposomal doxorubicin and cyclophosphamide as first-line therapy for patients with metastatic or recurrent breast cancer. Clin Breast Cancer. 2005;6(2):150-157.

41. Kurtz JE, Rousseau F, Meyer N, et al. Phase II trial of pegylated liposomal doxorubicin-cyclophosphamide combination as first-line chemotherapy in older metastatic breast cancer patients. Oncology. 2007;73(3-4):210-214.

42. Rau KM, Lin YC, Chen YY, et al. Pegylated liposomal doxorubicin (Lipo-Dox ${ }^{\circledR}$ ) combined with cyclophosphamide and 5-fluorouracil is effective and safe as salvage chemotherapy in taxane-treated metastatic breast cancer: an open-label, multi-center, non-comparative phase II study. BMC Cancer. 2015;15:423.

43. Gil-Gil MJ, Bellet M, Morales S, et al. Pegylated liposomal doxorubicin plus cyclophosphamide followed by paclitaxel as primary chemotherapy in elderly or cardiotoxicity-prone patients with high-risk breast cancer: results of the phase II CAPRICE study. Breast Cancer Res Treat. 2015;151(3):597-606.

44. Tuxen MK, Cold S, Tange UB, Balslev E, Nielsen DL. Phase II study of neoadjuvant pegylated liposomal doxorubicin and cyclophosphamide \pm trastuzumab followed by docetaxel in locally advanced breast cancer. Acta Oncol. 2014;53(10):1440-1445.

45. de La Fouchardière C, Largillier R, Goubely Y, et al. Docetaxel and pegylated liposomal doxorubicin combination as first-line therapy for metastatic breast cancer patients: results of the phase II GINECO trial CAPYTTOLE. Ann Oncol. 2009;20(12):1959-1963.

46. Wolff AC, Wang M, Li H, et al. Phase II trial of pegylated liposomal doxorubicin plus docetaxel with and without trastuzumab in metastatic breast cancer: Eastern Cooperative Oncology Group trial E3198. Breast Cancer Res Treat. 2010;121(1):111-120.

47. Sparano JA, Makhson AN, Semiglazov VF, et al. Pegylated liposomal doxorubicin plus docetaxel significantly improves time to progression without additive cardiotoxicity compared with docetaxel monotherapy in patients with advanced breast cancer previously treated with neoadjuvant-adjuvant anthracycline therapy: results from a randomized phase III study. J Clin Oncol. 2009;27(27):4522-4529.

48. Fabi A, Ferretti G, Papaldo P, et al. Pegylated liposomal doxorubicin in combination with gemcitabine: a phase II study in anthracycline-naïve and anthracycline pretreated metastatic breast cancer patients. Cancer Chemother Pharmacol. 2006;57(5):615-623.

49. Rivera E, Valero V, Arun B, et al. Phase II study of pegylated liposomal doxorubicin in combination with gemcitabine in patients with metastatic breast cancer. J Clin Oncol. 2003;21(17):3249-3254.

50. Adamo V, Lorusso V, Rossello R, et al. Pegylated liposomal doxorubicin and gemcitabine in the front-line treatment of recurrent/metastatic breast cancer: a multicentre phase II study. Br J Cancer. 2008;98(12):1916-1921.

51. Artioli G, Grazia A, Mocellin S, et al. Phase II study of neoadjuvant gemcitabine, pegylated liposomal doxorubicin, and docetaxel in locally advanced breast cancer. Anticancer Res. 2010;30(9):3817-3821.

52. Pircher M, Mlineritsch B, Fridrik MA, et al. Lapatinib-plus-pegylated liposomal doxorubicin in advanced HER2-positive breast cancer following trastuzumab: a phase II trial. Anticancer Res. 2015;35(1):517-521.

53. Rossi D, Baldelli AM, Casadei V, et al. Neoadjuvant chemotherapy with low dose of pegylated liposomal doxorubicin plus weekly paclitaxel in operable and locally advanced breast cancer. Anticancer Drugs. 2008;19(7):733-737.

54. Vorobiof DA, Rapoport BL, Chasen MR, et al. First line therapy with paclitaxel (taxol) and pegylated liposomal doxorubicin (caelyx) in patients with metastatic breast cancer: a multicentre phase II study. Breast. 2004;13(3):219-226.

55. Christodoulou C, Kostopoulos I, Kalofonos HP, et al; Study of the Hellenic Cooperative Oncology Group. Trastuzumab combined with pegylated liposomal doxorubicin in patients with metastatic breast cancer. Phase II Study of the Hellenic Cooperative Oncology Group (HeCOG) with biomarker evaluation. Oncology. 2009;76(4):275-285. 
56. Chow LW, Yip AY, Lang BH. A phase II trial of vinorelbine and pegylated liposomal doxorubicin in patients with pretreated metastatic breast cancer. Am J Clin Oncol. 2007;30(2):133-138.

57. Martin M, García-Donas J, Casado A, et al. Phase II study of pegylated liposomal doxorubicin plus vinorelbine in breast cancer with previous anthracycline exposure. Clin Breast Cancer. 2004;5(5):353-357.
58. Vici P, Colucci G, Giotta F, et al. A multicenter prospective phase II randomized trial of epirubicin/vinorelbine versus pegylated liposomal doxorubicin/vinorelbine as first-line treatment in advanced breast cancer. A GOIM study. J Exp Clin Cancer Res. 2011;30:39.

\section{Publish your work in this journal}

Breast Cancer - Targets and Therapy is an international, peerreviewed open access journal focusing on breast cancer research, identification of therapeutic targets and the optimal use of preventative and integrated treatment interventions to achieve improved outcomes, enhanced survival and quality of life for the cancer patient
The manuscript management system is completely online and includes a very quick and fair peer-review system, which is all easy to use. Visit http://www.dovepress.com/testimonials.php to read real quotes from published authors.

Submit your manuscript here: https://www.dovepress.com/breast-cancer---targets-and-therapy-journal 